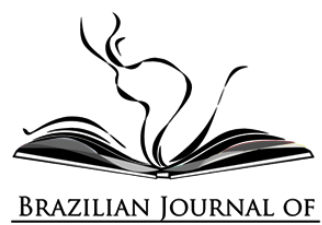

\title{
PENSAR A REALIDADE SE QUERES TRANSFORMÁ-LA'
}

\author{
PENSAR LA REALIDAD SI QUIERES TRANSFORMARLA \\ THINKING REALITY IF YOU WANT TO TRANSFORM IT
}

Joana A. Coutinho² iD

Universidade Federal do Maranhão, Brasil

\begin{abstract}
Resumo: A resenha aqui apresentada trata do livro Historia y Filosofía, de Caio Prado Jr., autor clássico do pensamento crítico brasileiro, agora traduzido ao espanhol pela Editorial último Recurso (Argentina) em parceria com o Núcleo Práxis-USP. A tradução do português para o espanhol, lançada em 2020, reúne textos originais selecionados da obra de Caio Prado Jr, marxista brasileiro. A organização do livro foi coordenada, pelo filósofo Yuri Martins, e é fruto de um trabalho coletivo cuidadoso de seleção e tradução empreendida por cerca de vinte pesquisadores de diversas áreas: historiadores, cientistas sociais, linguistas, economistas e até psicólogos, membros e colaboradores do Núcleo Práxis da USP, entidade político-acadêmica que ao longo da última década tem demonstrado compromisso com a difusão do conhecimento crítico e a formação política popular.
\end{abstract}

Palavras-chaves: Caio Prado Jr.; Colonização; Marxismo, Socialismo;

Filosofia-política.

Resumen: La reseña aquí presentada trata del libro Historia y Filosofía, de Caio Prado Jr., autor clásico del pensamiento crítico brasileño, ahora traducido al español por Editorial Última Recurso (Argentina) en alianza con Núcleo Praxis-USP. La traducción del portugués al español, lanzada en 2020, reúne textos originales seleccionados de la obra de Caio Prado Jr, un marxista brasileño. La organización del libro fue coordinada por el filósofo Yuri Martins, y es el resultado de un cuidadoso trabajo colectivo de selección y traducción realizado por una veintena de investigadores de diferentes áreas: historiadores, científicos sociales, lingüistas, economistas e incluso psicólogos, miembros y colaboradores. del Núcleo Práxis da USP, entidad político-académica que durante la última década ha demostrado

\footnotetext{
' Colaboração de Paulo lannone, claro que os problemas de interpretação são de minha inteira responsabilidade. 2 Doutora em Ciência Sociais: Política pela Pontifícia Universidade Católica de São Paulo. Professora na Universidade Federal do Maranhão; coordenadora do Grupo de Estudos de Hegemonia e Lutas na América Latina (GEHLAL) e pesquisadora do Núcleo Práxis- USP. E-mail: joaninahcoutinho@hotmail.com
} 
su compromiso con la difusión del conocimiento crítico y la educación política popular.

Palabras clave: Caio Prado Jr.; Colonización; Marxismo; Socialismo; Filosofía-política

Abstract: This book review aims to analyze the book "Historia y Filosofia", by Caio Prado Jr, recently published by Editorial Último Recurso in partnership with Núcleo Práxis-USP. The translation from Portuguese to Spanish was based on selected texts of the work of Caio Prado Jr, Brazilian Marxist. The book, coordinated by the philosopher Yuri Martins, is the result of a careful collective work of selection and translation undertaken by about twenty researchers from many areas: historians, social scientists, linguists, economists and even psychologists, members and collaborators of the Núcleo Práxis of USP, a political-academic entity which over the last decade has demonstrated a commitment to the diffusion of critical knowledge and popular political education.

Keywords: Caio Prado Jr.; Colonization; Marxism; Socialism; Philosophy; Politics.

DOI:10.11606/issn.1676-6288.prolam.2021.192139

Recebido em: 21/04/2021

Aprovado em: $24 / 72 / 2021$

Publicado em: 30/72/2021

O livro História e Filosofia ${ }^{3}$ de Caio Prado Jr (2020) recém-publicado pela Editorial Último Recurso, com sede na Argentina ${ }^{4}$, em parceria com o Núcleo Práxis-USP é um achado. Reúne textos inéditos de Caio Prado Jr., reconhecido historiador marxista, cujo tema de análise é a história e a filosofia. Um historiador-filósofo, cuja preocupação fundamental é propiciar recursos teóricos que nos permitam analisar a nossa realidade sem subterfúgios.

Não se trata de uma resenha da biografia de Caio Prado, mas vale a pena alguns dados que ampliam nosso conhecimento do autor. Caio Prado nasceu na cidade de São Paulo em 11 de fevereiro de 1907; dois anos depois da primeira experiência de Revolução na Rússia (1905). Morreu na mesma cidade em 23 de novembro de 1990. Caio Prado Júnior pertenceu a uma

\footnotetext{
${ }^{3}$ Título em espanhol: Historia y Filosofía.

${ }^{4}$ A Editorial Último Recurso é uma organização autogestionária, cuja base de atividade está nos princípios do conhecimento e na democratização do conhecimento.
} 
das mais ricas e influentes famílias de São Paulo. Teve uma educação esmerada como era comum aos de sua classe social: os estudos foram orientados, primeiro por professores particulares, depois no colégio São Luís, dirigidos pelos Jesuítas. Forma-se bacharel em ciências jurídicas e sociais aos 21 anos, pela Faculdade de Direito do Largo de São Francisco, mais tarde incorporada pela Universidade de São Paulo. Filia-se ao Partido Comunista do Brasil (PCB), em 1931. Tem uma vasta produção intelectual, sobre temas centrais para se pensar o Brasil e toda a América Latina, cujas reflexões nos fazem refletir a partir das classes populares. Foi um traidor de classe, de sua classe de origem!

Caio Prado considera que o processo histórico na América Latina foi bem distinto de outras nações do planeta, igualmente periféricas, em relação ao capitalismo desenvolvido; a particularidade é que não tivemos no continente uma burguesia nacional; e o caráter da nossa colonização que se estende para toda a América Latina- é que aqui as colônias foram marcadas por serem de exploração, diferente das colônias de povoamento nas zonas temperadas. O seu pensamento, assim como o de José Carlos Mariátegui (1894-1930), é bastante inovador e inaugura um marxismo original5; sem perder a perspectiva da totalidade, reforça a necessidade de se pensar o nacional, o local.

Pensar o país significa buscar compreendê-lo em sua totalidade e fugir das explicações simplificadoras que dão respostas superficiais a questões profundas: analisar a formação do país, como se constituiu sua gente e suas contradições.

Vamos ao livro História e Filosofia (2020, 336f). Numa tradução inédita para o espanhol, reúne textos, rigorosamente selecionados, de Caio Prado Jr. Fruto de um trabalho coletivo cuidadoso e sem recursos de apoio, a tradução - que tomou quatro anos de trabalho - foi empreendida por cerca de vinte pesquisadores de diversas áreas: historiadores, cientistas sociais, linguistas, economistas e até psicólogos, membros e colaboradores do Núcleo Práxis da USP, entidade político-acadêmica que ao longo da

${ }^{5}$ Ver Martins-Fontes (2015). 
última década tem demonstrado compromisso com a difusão do conhecimento crítico e a formação política popular, encontro feliz com uma editora autogestionária que coloca como ideia central ser uma editora militante.

O livro tem 10 capítulos e ainda um prefácio do historiador Lincoln Secco, uma bela introdução de seu organizador, Yuri Martins Fontes, filósofo, escritor, ensaísta autor de vários textos que discutem Brasil e América Latina $^{6}$ e coordenador do Núcleo Práxis da USP. Na Introdução, Yuri cumpre um papel fundamental de não só apresentar o livro, mas também o autor - para que jovens que não conhecem Caio Prado e sua obra tenham um panorama das questões principais que moveram sua produção.

O Prefácio é uma leitura leve e obrigatória, onde podemos observar a efervescência do pensamento caiopradiano em toda sua vivacidade. Lincoln Secco oferece aos falantes do espanhol (e a todos nós) uma belíssima apresentação dos traços marcantes do autor e de sua obra e, a originalidade do seu pensamento que coloca ainda hoje desafios não só aos brasileiros mas a todos latino-americanos. Vinculado ao Partido Comunista Brasileiro, Caio Prado manteve sempre sua autonomia como pensador e militante.

A primeira parte, Escritos político-historiográficos ${ }^{7}$-, recupera textos sobre a colonização do Brasil. Caio Prado observa os tipos de colonização ocorridas aqui e em terras de zonas "temperadas". As segundas, constituíram colônias de povoamentos, como um desaguadouro "dos excessos demográficos da Europa que reconstitui no novo mundo uma organização e uma sociedade à imagem e semelhança de seu modelo europeu". Nos trópicos ocorre exatamente o contrário, o que dará origem a uma sociedade original; são sociedades abigarradas, como definiu o

\footnotetext{
6 Veja, por exemplo, o livro Marx na América: a práxis de Caio Prado e Mariategui de Yuri Martins-Fontes, Alameda/Fapesp, 2018.

7 A primeira parte do livro, compõe-se de cinco capítulos, escritos em momentos distintos. Capítulo 1 Evolução política do Brasil (1933); Capítulo 2 URSS um novo mundo (1934); Capítulo 3 Formação do Brasil contemporâneo (1942); Capítulo 4 História econômica do Brasil (1945/1976) e Capítulo 5 A revolução brasileira (1966).
} 
sociólogo boliviano, René Zavaleta8 (1935-1984). O Brasil de hoje, observa Caio Prado, é um organismo em franca e ativa transformação, mas que não se sedimentou e não tomou forma. O mesmo se observa no terreno social: com exceção de alguns setores, as relações sociais, e em particular as de classe, conservam um cunho colonial. A essência da nossa formação, está no abastecimento do açúcar, tabaco, ouro e diamante, algodão e depois café para o comércio europeu. Caio Prado vê na colonização dos trópicos, uma vasta empresa comercial destinada a explorar recursos naturais. Importante recuperar o debate que se fazia à época: havia ou não feudalismo no Brasil. Alguns marxistas, como Astrojildo Pereira (1890-1965), Octávio Brandão (1896-1980) e Leôncio Basbaum (1907-1969), defendiam a tese do "feudalismo em declínio" como a causa do atraso. Por esse caminho tornava-se necessária uma revolução democrático-burguesa (Del Roio, 2016). Já Caio Prado sustentava que no Brasil não houve feudalismo -apoiando-se por exemplo no fato de que o povoamento do país era rarefeito, não contribuindo à consolidação da servidão; para o pensador marxista, o que houve por aqui foi um escravismo: desde os primórdios articulado comercialmente com o capitalismo europeu que se consolidava.

\section{Ao abordar a Economia e a agricultura de subsistência na colônia} (1942), Caio Prado afirma que a economia se assenta em algumas bases muito precárias, não constitui uma infraestrutura própria e tampouco conta com forças próprias e existência autônoma. Se uma conjuntura internacional favorece a um produto qualquer, isto impulsiona seu funcionamento; no entanto, a economia volta a cessar se essa conjuntura por alguma razão se rompe ou caso os recursos naturais se esgotem (PRADO, 2020, p.143). O que nos leva a pensar nas implicações de uma economia completamente subordinada —em vias de se tornar um capitalismo periférico e dependente.

O resultado é que vivemos uma realidade que ainda parece sofrer dos mesmos males: voltada para fora e incapaz de prover as necessidades da

\footnotetext{
8 Abigarradas, porque são sociedades heterogêneas, com diversas culturas e modo de produção: ocorreram em um mesmo cenário o feudalismo e o capitalismo superpostos, o que proporcionou por exemplo, que Potosí, o maior caso de descampesinização colonial (Zavaleta, 2009).
} 
sua população. A produção de subsistência, que alimenta os habitantes do campo, difere muito da realidade dos centros urbanos: estes têm que recorrer à importação, já que a produção interna não é suficiente para lhes suprir as necessidades. Curioso que hoje as grandes plantações, voltadas a suprir o mercado externo, tenham transformado alimento em "commodities"; ou seja, nossas questões do passado persistem. Em toda América Latina, desgraçadamente, o avanço do imperialismo significa (significou) uma relação de subalternidade, perda de soberania: o capitalismo dependente periférico não foi capaz de criar uma burguesia que defenda os interesses nacionais, como nos lembra Eduardo Galeano (1940-2015) "dominantes hacia dentro, dominadas desde fuera" (2004, p.17) e, reagem com dureza a qualquer tentativa de mudança por mais milimétrica que seja.

Um outro aspecto que parece nos fazer voltar no tempo é: como se tornou atual, nesse processo de colonização e necessidade de povoamento e o papel exercido pelos bandeirantes na captura de indígenas e escravos.

Caio Prado descreve no texto A Sociedade Colonial ${ }^{\mathbf{9}}$ (1942), de uma maneira clara e objetiva, o significado do bandeirismo paulista: processos brutais que os portugueses utilizavam para forçar os indígenas ao trabalho. Faziam isso percorrendo o Brasil de leste a oeste, de norte a sul, até chegarem ao sertão. Hoje, um movimento da periferia de São Paulo revive o debate quando atiça fogo na estátua do conhecido bandeirante, Borba Gato $^{10}$ e reaviva a reflexão sobre os símbolos, espalhados pela cidade, que cultuam o passado. Neste caso, o passado de exploração e opressão.

Não podemos deixar de mencionar o interessante texto $\boldsymbol{D}$. João VI no Brasil $^{17}$, que trata da nossa independência. A vinda da família real para o Brasil, em 1808, significou a emancipação política, mas de uma forma peculiar: diferentemente do que acontece nos países vizinhos, em que

\footnotetext{
${ }^{9}$ La sociedad colonial. In: Capítulo 3. Formación del Brasil Contemporáneo (1942).

10 A Estátua, localizada na Praça Augusto Tortorelo de Araújo, no bairro de Santo Amaro - São Paulo, é uma homenagem a Borba Gato (1628-1718), bandeirante paulista, cuja proeza além de caçar indígenas e escravos fugidos, era desbravar o sertão em busca de ouro e diamantes. Um movimento autointitulado "Revolução Periférica" ateou fogo na estátua em julho de 2021, como protesto ao símbolo que representa essa forma de opressão.

"D. João VI en Brasil. In: Capítulo 1 Evolución Política del Brasil (1933).
} 
foram rompidos os laços que os subordinavam às nações europeias. A diferença crucial é que enquanto outras nações conquistavam sua independência nos campos de batalha, aqui foi o próprio governo metropolitano que, pressionado, se viu obrigado a transformar a colônia em sede da monarquia, lançando as bases de sua autonomia. Caio Prado não cai na explicação fácil da ausência de lutas, de que não tivemos lutas internas; ao contrário, descreve com rigor as revoltas, a Balaiada, por exemplo. Mas mostra que nenhuma delas teve força e organização necessária para uma sublevação das massas. O principal aspecto da balaiada foi a caudilhagem - e isso não permitiu que a revolta se convertesse em um movimento que pudesse ter resultados mais profundos.

Ainda nessa primeira parte, destaco o capítulo, URSS: Um Novo Mundo ${ }^{12}$, sobre a Revolução Russa. O relato da viagem que faz à terra de Dostoiévski impressiona pela sua observação aguda do que acontecia naquele momento e, mais ainda, pela descrição da participação dos trabalhadores no processo. No trem que o levava a Leningrado, Caio Prado pôde presenciar uma verdadeira assembleia política entre os passageiros, incluindo mulheres e empregados do trem, que participavam de um "debate acalorado" no qual palavras como socialismo, soviete, capitalismo eram ditas constantemente e com clareza do conteúdo.

Neste mesmo escrito, Caio Prado enaltece as transformações pelas quais está passando a sociedade soviética, "uma democracia das massas e não da minoria". O socialismo é a expressão mais completa e perfeita que se pode imaginar para uma classe social nas condições do proletariado. Mas o mais importante não é debater o socialismo em si, mas o caminho que nos leva ele: as organizações políticas que levaram a sério a tarefa da condução para a realização de um programa. É mister, para uma sociedade comunista, uma transformação completa das ideias e concepções da humanidade atual. Enquanto domine o individualismo acentuado, fruto deste sistema, temos de compreender que uma sociedade comunista

${ }^{12}$ Capítulo 2 URSS Un Nuevo Mundo (1934) 
plena é impossível; antes é necessária a tarefa de reeducação dos homens e das mulheres sobre a base de uma solidariedade social compatível com essa nova sociedade. Nesse sentido, ele comunga com Antonio Gramsci (1891-1937) que fala da necessidade de uma reforma cultural e moral, pilar para a reeducação em uma sociedade comunista.

O livro-ensaio $\boldsymbol{A}$ revolução brasileira ${ }^{13}$, escrito em 1966, começa por discutir sobre o termo: revolução expressa o processo histórico marcado por "reformas e mudanças econômicas, sociais e políticas sucessivas" que dão origem a transformações estruturais da sociedade. Não é um momento do êxtase, mas todo o processo de construção. O ritmo da "história, não é uniforme". Ao contrário; o texto, parece descrever as desventuras que vivemos nos dias de hoje. Afirma que o Brasil se encontra em um momento decisivo que leva a manifestações de descontentamentos e insatisfação generalizada. Situação que é causa e efeito da incoerência política, da ineficiência, dos desequilíbrios sociais, das crises econômicas e financeiras.

Em um tempo no qual se discute com tanto afinco o câncer da sociedade brasileira, o racismo estrutural, não poderíamos deixar de mencionar a passagem do texto Vida Social e Política ${ }^{14}$, em que Caio Prado (2020, p.168), ao discutir a formação e organização do Brasil, menciona a presença do negro e do escravo. Há que fazer uma distinção, diz ele, difícil, mas necessária, de como o escravo protagonizou a cena, mas o negro aparece em raras oportunidades. O papel do africano, diz ele, teria sido muito diferente na formação cultural da colônia se lhe tivesse sido concedida a mínima oportunidade para que se desenvolvesse. Elementos que ajudam a formular o "racismo estrutural" na sociedade brasileira.

A segunda parte do livro concentra os Escritos filosóficos e manuscritos inéditos São quatro capítulos com passagens selecionadas de alguns de seus principais livros filosóficos: Dialética do Conhecimento ${ }^{15}$

\footnotetext{
${ }^{13}$ Capítulo 5 La revolución Brasileña (1966)

${ }^{14}$ Vida social y Política In: Capítulo 3 Formación del Brasil Contemporáneo (1942).

${ }^{15}$ Dialéctica del Conocimiento
} 
(1952); Notas introdutórias à Lógica Dialética' ${ }^{16}$ (1959); O mundo do socialismo $^{17}$ (1962); e Que é Filosofia' ${ }^{18}$ (1981). Traz ainda um derradeiro capítulo, "Cadernos e correspondências"19", com coletânea de manuscritos jamais publicados do autor, pertencentes ao Arquivo do Instituto de Estudos Brasileiros da USP.

\section{Destaca-se Carta ao Comitê Regional de São Paulo do Partido} Comunista de Brasil (novembro de 1932). Responde a uma comunicação interna em que é acusado de tentar fundar um periódico pequeno-burguês. A linha editorial é marxista-leninista, responde Caio Prado, e do contrário não Ihe interessaria. Mas a obrigação de todo mundo é tentar, em lugar de cruzar os braços, e declarar de antemão que atuar é inútil e impossível. 1937 (Paris, dezembro de 1937). Escreve nessa pequena nota sobre a Revolução de 1930, no Brasil, e suas causas: a evolução centralizadora da política brasileira, provocada por vários fatores. Uma das causas não se extirpa, velhos costumes de uma tradição do dia para a noite. As condições objetivas se haviam modificado profundamente, no entanto, não houve uma maturidade política no país, e Carta ao "companheiro" Evaldo da Silva Garcia ${ }^{20}$ (maio de 1946) responde a uma pergunta dirigida a ele sobre sua posição política. Caio Prado responde: "continuo onde sempre estive, desde que me reconheço como gente, sou comunista, membro do $P C B$, tenho buscado aí harmonizar minhas convicções com uma linha política. Escrever para um comunista não é fazer o que the agrada, não é buscar louvores, é contribuir na formação e divulgação da teoria revolucionária do marxismo" (PRADO, 2020, p. 326).

Dialética do conhecimento ${ }^{21}$ (1952), sem alongar muito, destacamos como texto didático; faz uma breve apreciação do que seja o conhecimento metafísico e da diferença crucial para o conhecimento dialético. Qualquer leigo é capaz de compreender que o conhecimento metafísico não nos

\footnotetext{
${ }^{16}$ Notas Introductorias a la Lógica Dialéctica

${ }^{17}$ El Mundo del Socialismo

${ }^{18}$ Qué es la Filosofía

19 Cuadernos y Correspondencia

${ }^{20}$ Carta al "compañero" Evaldo da Silva Garcia

${ }^{21}$ Dialectica del Conocimiento
} 
leva à compreensão completa e tampouco à necessária transformação. Parte de um exemplo simples, mas não simplista: o universo. 0 conhecimento metafísico é a consideração geral do universo; e o que constitui seu ponto de partida são sempre os indivíduos que compõem este universo, bem como a individualidade deles. Diferente do conhecimento dialético; a dialética não considera primeiro os indivíduos, seres, coisas, para depois considerar suas relações. Ou seja, a dialética em oposição ao método metafísico considera antes as relações, o "conjunto" e a unidade universal onde transcorrem tais relações. A dialética, afirma Caio Prado Jr., é essencialmente um método de pensamento e conhecimento.

No ensaio sobre o mundo do socialismo, o autor fala sobre países que visitou; diz que não foi conhecê-los para julgá-los, mas ao contrário, para analisar as soluções oferecidas nestes países aos problemas da revolução socialista. Interessa as lições que esses países deram, positiva e negativamente, no sentido de que cada qual "mostra o que se deve fazer e o que se deve evitar". Mas o que é então o socialismo? Um mundo fundado em um princípio oposto, onde a cooperação entre os homens é o princípio do esforço comum, conjugado para os mesmos fins, que são de todos. Já sobre a questão da liberdade, ele faz um traço claro e definido do significado da liberdade individual nas democracias burguesas. Esta, está fundada essencialmente nos interesses individuais, que se chocam com a liberdade dos outros indivíduos; que se restringem "desde o momento em que um começa a atuar e deve deter sua marcha pelos interesses contrários". No socialismo, ao contrário, o ponto de partida é o interesse coletivo; a liberdade individual não é uma premissa. Por liberdade se entende a faculdade, a possibilidade e a oportunidade do indivíduo se realizar. Portanto, a liberdade nas democracias burguesas não passa de ilusão - algo impossível de se realizar plenamente.

O livro, que trata de tantos temas pertinentes aos dias de hoje, deveria ser amplamente divulgado aos falantes hispânicos, porque embora voltado a pensar o Brasil as questões e temas trabalhados pelo autor diz respeito a toda América Latina: as nossas colonizações, nossas organizações políticas 
e as nossas particularidades como continente. E, óbvio, aos lusófonos, para que aqueles que não tiveram acesso à obra completa do Caio Prado possam usufruir desses textos diversos e abrangentes, que ao fim e ao cabo dão um panorama do todo da obra do autor.

\section{Referências}

DEL ROIO, Marcos. "Sodré e o feudalismo no Brasil: uma tentativa de atualização do problema". Revista Crítica de Sociologia e Política. vol. 7, n. 2, jul.-dez. $2016 . \quad$ Disponível em: https://www.revistaterceiromilenio.uenf.br/index.php/rtm/article/download/1 13/89/. Acesso em: 21 dez. 2021.

GALEANO, Eduardo. Las venas abiertas de América Latina. México: Siglo Vientiuno, 2004.

MARTINS-FONTES, Yuri. O marxismo de Caio Prado e Mariátegui: formação do pensamento latino-americano contemporâneo. Orientador: Lincoln Ferreira Secco. 2015. 275f. Tese de doutoramento. Programa de Pós-Graduação em História Econômica, Universidade de São Paulo, São Paulo, 2015. Disponível em: https://www.teses.usp.br/teses/disponiveis/8/8137/tde-01072015-143501/publi co/2015_YuriMartinsFontesLeichsenring_VCorr.pdf.. Acesso em: 21 dez. 2021.

MARTINS-FONTES, Yuri. Marx na América: a práxis de Caio Prado e Mariátegui. São Paulo: Alameda, 2018.

PRADO JR., Caio. Caio Prado: Historia y Filosofía. São Paulo: Editorial Último Recurso/ Edições Núcleo Práxis-USP, 2020 (1ra edición).

ZAVALETA, René. La autodeterminación de las masas. Bogotá: Siglo del Hombre Editores/ Clacso, 2009. Disponível em: http://biblioteca.clacso.edu.ar/ar/libros/coedicion/zavaleta/. Acesso em: 21 dez. 2021. 